\title{
Research on the Performance and Governance of the "Lazy Government" by the Unit Leader
}

\author{
Jiajun Xie \\ The Administrative Department of the School of Public Management, Jinan University, Guangzhou, China \\ Email: 2568523379@qq.com
}

How to cite this paper: Xie, J.J. (2018) Research on the Performance and Governance of the "Lazy Government" by the Unit Leader. Open Journal of Social Sciences, 6, 106-118. https://doi.org/10.4236/jss.2018.61008

Received: December 20, 2017

Accepted: January 19, 2018

Published: January 22, 2018

Copyright $\odot 2018$ by author and Scientific Research Publishing Inc. This work is licensed under the Creative Commons Attribution International License (CC BY 4.0).

http://creativecommons.org/licenses/by/4.0/

c) (i) Open Access

\begin{abstract}
"Lazy politics" problem has always existed, under the new political norm, the phenomenon of local government officials "lazy politics" is more prominent. Under this background, the author studies the phenomenon of "lazy politics" and its governance under the new normal politics. First of all, the "lazy politics" refers to the corresponding "diligent", including "omission", low administrative efficiency, no due diligence, and the performance of the new period in the new "lazy politics" into the enthusiasm is not high, the quality is not high, the efficiency is not high, do not want to face the new environment and new problems and new situations, not as well as to avoid the risk and responsibility for not. And then the reasons of laziness from individual, unit and system level are analyzed. In the end, some feasible suggestions are put forward.
\end{abstract}

\section{Keywords}

Local Government Officials, Lazy Politics, Political New Normal, Solution Oriented Government Theory

\section{The Proposal of the Problem}

\subsection{Research Background}

Since the Eighteenth National Congress of the CPC, under the accountability system in high corruption, corruption phenomenon is gradually reduced, but it produces a new form of corruption-lazy political phenomenon, "the body is not as in the post, with a more general, Yong Zheng lazy government ministers, is also a kind of corruption [1]." Premier Li Keqiang in 2015 government work report, pointed out the cadres not official, lazy politics and lazy political phenomenon. In the provinces, city, county, township, with the three guidelines for ethical behavior and the three basic rules of conduct activities, carry out the lazy 
government lazy politics, the problem is not official special treatment activity.

Taking Guangdong Province as an example, according to the State Council on the second national inspection second batch verification accountability work deployment, for lazy politics not as the typical problems of Guangdong Province in 2015, according to the law of the city, 25 people accountability, party and government discipline, the 5 people at department level and 18 people at county level, 2 people at Township level. The 3 districts of Zhanjiang City, Shenzhen, Meizhou, Zhanjiang and 3 other cities and Shantou City, Leizhou City, Haojiang District of Shanwei City, Lufeng city, the problems of financial capital precipitation, were given to the above city and 13 district responsible administrative warning, admonishing conversation, admonition processing. A higher level of protection funds at the end of 7 in Zhuhai, Shaoguan, Jieyang and 3 other cities, responsible for 3 people in charge of the municipal government and the financial department is mainly responsible for admonishing conversation [2]. It is necessary to study the phenomenon of "lazy administration" by the leading officials of the unit.

\subsection{Significance of Research}

1) Academic significance: Through the "risk expectation" and "interest" and "political promotion" perspectives of organic integration, and based on the theory of public choice rational person hypothesis "and" prospect theory, "explain the formation of local officials choose frame lazy political behavior in the new situation, the lack of help to compensate for officials" lazy politics "part of the research contents, form a systematic research and summary. On the other hand, it summarizes and generalizes the phenomenon and behavior of lazy officials in domestic scholars, and puts forward a more comprehensive view based on previous views. It has a certain significance for the supplement and expansion of officials" "lazy politics" content research.

2) Practical social significance: First of all, from the perspective of the officials themselves, we explore the reasons why officials are lazy, and put forward corresponding policies and measures to encourage their active officers to give officials the space and protection of their bravery, reflecting the humane care of government officials, which has certain practical significance. Secondly, from the perspective of government officials, because of lazy political phenomenon and behavior, both for the individual and unit, the government and the public, there are hazards, the need for timely control and governance of this phenomenon, the reasons for official lazy political behavior of scientific and effective measures to provide the reality help for the government in the management and regulation of officials' behavior process. At the same time, we should make a rigorous investigation and measurement of the "lazy government" phenomenon and behavior of grass-roots government officials with scientific methods, and analyze the current situation of the grass roots government officials' lazy politics on the basis of scientific assessment, which has certain reference value. 


\section{The Analysis of the Status of the "Lazy Government" of the Unit Leaders}

Whether the central or the local, the official "lazy" phenomenon cannot be ignored.

\subsection{The Basic Understanding of the Official "Lazy Government"}

"Lazy politics" as the name suggests, the diligent relative. The official "lazy government" refers to the negative action and inaction taken by the government staff or government departments in performing their job duties or legal obligations. In other words, diligent refers to public officials to perform their duties, due diligence; conversely, is lazy politics [3]. Those who failed to do, carefully, timely, responsible, in-depth work officials, can be called lazy politicians. To carry out the work style of the door hard, ugly face "the problem has changed, but in reality the difficult are still traceable". The reduction of administrative approval and the implementation of the list of powers are bound by the phenomenon of "visible hand" disorder, but the actual landing of policy is more or less biased. For those who are not conducive to promote their own interests, but their own duty, some officials under the guise of "decentralization", cannot do, can evade is shirk, think of ways to make a detour, not as. However, for those matters of interest, we still need to do everything possible to demonstrate its necessity and rationality, so that we cannot simplify our defense, but the logic behind it cannot be deliberated. In addition, officials looking forward to "excessive security" have not been motivated to take the initiative.

\subsection{The Type and Performance of the "Lazy Government" by the Leadership of the Unit}

After Premier Li Keqiang put forward the issue of "lazy politics" of officials, domestic scholars' research on the phenomenon of "lazy politics" sprung up like mushrooms. Domestic scholars generally divided officials' laziness into three categories: they didn't want to do it, but they didn't do it or dared to do it [4] [5]. This paper based on the basis of the reality of the existence of the existence of a variety of unit officials "lazy politics" forms are listed and described, some of the units leading officials at work exist in different forms of "lazy", according to the "lazy politics" and its influence can be divided into "lazy politics" and the severity of the adverse effects of "lazy politics" heavily influence, "lazy politics" to a lesser extent influence.

The first is that laziness "is serious and affects bad omission": 1) covet is comfortable and feels lazy. Some leading officials are tired because they can't find pleasure in their work for a long time. They are tired of work and lead to unintentional work. Or to treat their own work, the spirit of the poor, low-spirited face tired, just want to live comfortable, dawdle; 2) "lazy" indulged in his own elegance. Some officials put their work aside, often at work will be the main focus of busy, calligraphy and painting, photography, chess, in an attempt 
to muddle through, some of the original project run by eating and drinking of cadres picked up the camera, take pictures, concentrated on Sun photos, look for the so-called sense of presence in the circle of friends, but in the working time without job; those who spend public funds cadres began to have advantageous to both public and private interest and a table of the "scholar's four jewels" Beitie, Huapu full frame, and many famous enthusiasts dating, but not in contact with the common people. It takes a lot of time and energy to spend time with personal interests, and to throw the people aside.

The second is that the "lazy government" has a greater impact on the greater degree of misconduct: 1) to hide information and use the authority to assign jobs to subordinates' laziness: the main reason is to report information on the hidden information so as to reduce unnecessary trouble. Especially in the most common base is the leading cadres in the report, deliberately concealing the petitioners, bad news. Assign the job to the subordinates to reduce their workload. It is understandable that a unit leader assigns and coordinates a reasonable task to a staff member, but in fact, leaders sometimes use their power to attach themselves to their work tasks, which is "lazy politics". For example, the grass-roots leading cadres should walk to the masses of people and experience effectively, but some leading cadres like office work and do not want to go below the grass-roots level; 2) the quality of work is not up to the standard of "loose lazy", as the name suggests is the attitude towards the matter is not serious, to do things carelessly, resulting in work quality standards. Or only do the work surface, actually does not solve the problem effectively, the inner is still loose is not strong, the general performance of lip service. Or the leading officials relax their demands on themselves, have no sensitivity to the situation, and have no sense of keeping pace with the times; 3 ) not to work actively and slow lazy, refers to the work done is not timely, the work cannot be completed, the task is not completed in the time period, slow action, poor execution, can procrastinate, delayed; 4) for the sake of convenience, labor-saving "lazy", such as some of the leadership of formalism in the implementation process of virtual execution-to implement the conference meeting, to document the implementation of documents; 5) laziness to avoid difficulties and avoid responsibility. In the face of difficulties detour, accident responsibility to find a scapegoat, difficult thing for.

The third is that the low degree of "lazy politics" which affects the general inactivity: 1) we have barely finished the task, but we haven't done our best in the "Jane laziness": leaders of these units only want to get through and cope with the work, to serve our people, and lack the spirit of pioneering and innovation. In the era of reform and development, officials have no spirit of sharp innovation on the road of reform, and to a certain extent, it hinders the process of reform; 2) careless negligence of the details of the lazy. Do not pay attention to the details of the work, not strict, there are a small number of defects. Although it does not affect the completion of the work in general, it has not been perfect for the work and has not been treated strictly and wholeheartedly. 
In general, as long as no accident, would prefer not to work, not to live hard, just go "and" not to do things, not risk; the organization of the examination, no fault, "is the leading officials of certain units generally mentality lazy politics". Some of them do not want to keep the status quo, scale, lack of enthusiasm and enterprising consciousness, encounter a problem or make a detour, or will issue; some people not to work, fear of failure, fear of risk, worry about stepping on the red line, violated the rules of doing things lack of courage and pioneering spirit all day long, timid, others worry about personal gains and losses; "no", the new economic norm put forward higher requirements for the work of cadres, some cadres are not familiar with the deepening of reform, adjust the structure, change the way of the new task, by eating and drinking Department feelings, relationships to run the project of the old style still exist. Not only cannot solve new problems, and do not take the initiative to learn, study, and work, the idea is not wide, often miss the point, at a loss what to do.

\section{The Harm of "Lazy Government" by the Leader of the Unit}

If you can't correctly understand the unit leadership officials "lazy politics" phenomenon, this phenomenon can't curb the development and spread to the public, the society and the nation will bring an indelible harm. On the one hand, the lazy politicians' appeals to the people, whether or not asked, reduced the credibility of the government, differentiated the flesh and blood ties between the people and our party. On the other hand, the lazy politicians made the overall administrative efficiency of the government lower and affected the process of socialist modernization. If corruption is the fatal injury of the party and the state, lazy politics is a chronic disease of the party and the state, which occasionally appears for a while.

\subsection{The "Lazy Government" Directly Causes the Work to Be Unfinished, the Performance of the Unit Is Poor, and the Public Interests Are Damaged}

The leading official "laziness" means the task of doing a good job without heart, effort and responsibility. Taking environmental group events as an example, leading officials often ignore the opinions of the people and the views of petitions, which have damaged the rights of public rights and participation. The contradiction between the days and months multiplying once ignited it will evolve into a conflict, eventually forced by public pressure, the government had to suspend the project or construction unit, also means that they did not complete the task, the unit performance also will decline.

\subsection{The "Lazy Government" Indirectly Affects the Government's Image and Credibility}

Because of the laziness of some leading officials, the image of the unit, even the whole government and the party members and cadres, will be stigmatized. Trust 
is a cumulative process, and it takes time and energy to build it. The establishment and consolidation of government credibility depends on the success of the government to meet the needs and expectations of the public [6]. Leading officials' laziness and low work efficiency will damage public interests, and the public will also feel a sense of distrust. The accumulated credibility of the government will be dispelled. Such as now, "the door well into the face look good, just don't work". If the government does not do it, can the interests of the masses be not damaged? After a long time, the masses will be resentful to these lazy officials. From resentment of individual cadres to resentment of the government, they will greatly affect the credibility of the government.

\subsection{Lazy Politics Does Not Curb Pollution Will Form the Political Ecosystem}

The "lazy politics" of leaders of a unit will first affect the work attitude of subordinates and form imitation psychology, which will affect the working status of the whole unit. Further spread to other units will affect the development of the whole political and ecological environment. Even spread to the society and affect all walks of life, once the atmosphere is formed, it will have a negative influence on the local morality, people's work attitude and professionalism [7].

\section{Analysis of the Reasons for the "Lazy Government" of the Unit Leading Officials}

The direct reason for the phenomenon of "lazy government" can be divided into laziness and no desire to do, because of incompetence, too lazy to do it, lazy to do it, and the behavior of avoiding laziness under external pressure is more focused on the lazy political behavior caused by pressure. However, lazy people who are lazy, lack of ability and lazy under pressure and risk can analyze their lazy reasons from individual level, unit level and institutional level.

\subsection{The Reasons for the Individual Level}

First, the lack of belief in officials and the lack of ideas do not want to do. Ideals and beliefs reflect the party members and cadres of the ideological consciousness and spiritual realm, is longing for the Party cadres and the goal and direction of internal power to carry out the work of the. Some officials did not adhere to the ideals and beliefs as the core, to seize the world outlook, life, and values of this master switch, "not" adhere to the people-oriented, respect the dominant position of the masses, forget the history and reality tell us the party is the fundamental of the people, rooted in the people, serve the people, causing some party members and cadres lack an example of misconduct, and thus lost the spirit of the lack of calcium, suffering from rickets" [8]. No spiritual power support, leading to "become a common phenomenon in charge". When the "official" is to serve the state and serve the people, "serve as an official and benefit one party". But, when such an "officer" is too hard to pay too much. But they 
just regard the official position as only a means of making a living, just want to be comfortable, work not to mind, more than one thing is less [9].

Second, a person's lack of ability can't do it. The level of the ability and quality of officials cannot adapt to the needs of the development of the Department, and cannot meet the needs of the job. Especially in the new situation, these people can't understand the spirit of the party's policies. They can't grasp the specific facts of the grass-roots units, and can't find the right starting points to carry out the policy. Or because of the status quo, work by experience, in the face of new situations and new problems, the old way does not work, the new approach does not use without the ability to panic consciousness, lack of a sense of crisis, don't know how to do the work. For example, local officials, local government has long tasks are to GDP priority, based on GDP performance, the whole county (city) work around the full investment, resource development, development of special industries, a large demolition and construction, the county (city) leaders of the GDP growth is full of enthusiasm, joy. In 2014 promulgated the new "selection and appointment of leading cadres work regulations", stressed the need to change the "evaluation model only GDP performance concept, to study comprehensively and objectively on the leading cadres of political quality and morality, scientific development, the style of performance, performance and other aspects of the situation. However, some leading cadres simply don't think that they should be heroes in terms of GDP. They are not at all clear about the promulgation of the new regulations. They do not know how to carry out their work under this regulation. If they take a wait-and-see attitude, they will not be able to make any deviation from their achievements.

Third, they are afraid to offend people and do not dare to do it, but choose to escape from the lazy government. First, under the current system, officials are liable to be offended. What do people often need to negotiate, with superior leadership and departments to solve the problem, means an increase in the leadership and colleagues work virtually, it will make people feel unhappy, easy to offend people, think you are nothing to do, the relationship between colleagues is not handled well, naturally leads to their reputation, public opinion the evaluation score is not high, this atmosphere, who is willing to be good, for the people wholeheartedly. Plus, "do not have a good result". Do means responsibility, the risk is also increased, as mentioned above, the fear of accident responsibility "so as not to do. Secondly, officials are not only facing the risk of accountability within the system, but also facing the public daily, network accountability, risk media help, with seamless media and public communication platform, civil supervision power to reach the height of hitherto unknown substance, the main supervision officials extended to all Internet users. In the development of science and technology, the speed and transmission of all kinds of events present a high degree of interaction under the condition of no time and space restrictions. It means that they need to face more risks than they think. They are not only conventional, but also under the unconventional events. They 
often appear caught off guard.

\subsection{The Cause of the Unit Level}

First, the work unit does not want to do one culture influence. Some local political ecology even more wrong, less work has become the unspoken rule, others do not you do it, the gun fight bird, don't give yourself trouble, once some of the work culture is not positive, is a lazy government, officials under the nurture could be formed don't want to do the thinking and behavior.

Second, the group does not unite as an excuse for being lazy. Between officials dubious, lack combat team. The group on the surface, the contradiction is not obvious, keep on good terms with each other. However, when a specific problem is encountered, the potential contradictions will be exposed. In the face of contradictions, want to solve the problem becomes difficult to choose as worldly-wise and play safe. Each is in his own affairs, and the team lacks cohesion. A team is not the core of the collective, team members of orders and prohibitions of each act in his own way. Each blow each number in the work, each singing a different tune, lacking spirit of cooperation, mutual unconvinced, no mutual cooperation and mutual coordination. The two is that there is an obvious fissure between each other. On the surface of nonaggression, privately to attack each other, once encounter endanger their own interests, will play a sword. Three, form a faction factional, exclusion, cultivate private forces. In this kind of work, there is no correct collective opinion on some problems. The sense of collective honor has disappeared, and the work will be in a semi paralyzed state.

Third, the variation of the political and ecological environment does not dare to be lazy. As the saying goes in official circles: As ingeniously, dry as see, see not naughty, so up is not necessarily strong, standing still is not necessarily low. Attack each other and the team is paralyzed. Internal intrigues, slander, and debate with each other. Many officials do not dare to work. In the competitive and officialdom, people will pay more attention to doing more things. Once a mistake is made, people who have ulterior motives will magnify and disrupt, so that those who do not dare to do things.

\subsection{The Cause of the System Level}

First, the current salary system and the lack of incentive system strengthen the behavior that officials do not want to do. The administrative organs have greatly adjusted the salaries and salaries of public officials, standardized the payment of all kinds of grants and allowances, and the decline of "bright income" such as salaries, bonuses and so on, especially in high level and high level leading cadres. At the same time, because of the strong push to punish corruption and work style construction, the "dark income", such as official's duty consumption and grey income, have also declined sharply. Under this dual role, some public officials have insufficient work motivation, waiting to wait and see the spread of emotions, and there is a state of mind that does not want to do a 
job. Most of the grass-roots government officials loyal to the calculation of personal gains and losses, rather than because of mistakes what setbacks are not, not in lockstep, a peace, maybe a chance to be a meteoric rise. Therefore, they are afraid of the problem, overcautious, afraid of a handle, encountered contradictions in hiding, encounter difficulties detour.

Second, fault-tolerant mechanism of disclaimer is not perfect, which leads to the lazy politics that dare not break through. Some reform measures encountered "obstruction" hard landing, largely related to the poor state, and full of worries. However, there are always some mistakes in the way of exploration. It is a protection for innovators and an encouragement for innovators to establish fault-tolerant mechanisms, differentiate between them, explore errors and violate discipline. The overall deepening of the reform is a systematic project with many threads and a heavy task. Some party members and cadres are more general more mistakes, less work and less error, mistake do not go wrong, that many people to work, there may be ten things do nine things, one thing no good, give others a bad impression, so in practice is not knowing, less is better, but not before worldly-wise and play safe, the habit of others, others are. These phenomena fully illustrate the necessity of establishing fault tolerance mechanism.

\section{Thinking about the Countermeasures of "Lazy Government" of the Unit Leading Officials}

In 2015 the government work report for the first time, governance Yung lazy governance should be included, put forward: "to improve the performance appraisal mechanism, with outstanding achievements, to praise; the working poor, to interview is not official, admonishing; the lazy government ministers, to the public exposure, firmly held accountable [10]." Due to the reasons of lazy politics, there are many schools needing to establish a more comprehensive governance system.

\subsection{To Strengthen the Standard Supervision of the Laziness of the Leadership and to Form the Idea of Active Laziness}

First, the guide unit leading official attitude, establish official people diligent concept. As the management of public affairs officials must reverse the "official post for an official cover" mentality, establish the correct official people thought, set up "to carry the black gauze cap act for the people" concept. "When officials are not making decisions for the people, they should go home to sell sweet potatoes". When they have power, they must shoulder corresponding responsibilities, because these powers are all given by the people, which means that they should bear the due responsibilities for the people. Truly serve the people, to do practical things for the people, safeguard the fundamental interests of the masses, not only of themselves.

Second, to guide the formation of learning concept and unit leadership ability correctly, lay the foundation for diligent work. With the development 
of various undertakings and the strengthening of government service functions, the content of work is more and more diverse. This requires officials to adjust themselves and enrich themselves with constant learning and constantly adapting to the new deal mentality. The quality and working level of officials need to accumulate experience continuously in their daily work and study, constantly explore and explore their working methods, combine theory with practice, accumulate experience and enhance their working ability in practice.

Third, guide unit officials dealing with social supervision, weaken the officials fear the mental disorder and not diligent. In the optimization of the internal environment, create a stimulating atmosphere, diligent.

\subsection{In the Optimization of the Internal Environment, Create a Stimulating Atmosphere, Diligent}

First, create a positive and promising official "diligent" working environment in the unit. The influence of culture on people has the characteristics of imperceptible, far-reaching and lasting, which is generally not tangible and coercive. The world outlook, the outlook on life and the values are the core and symbol of people's cultural accomplishment. A person's outlook on world, life and values is formed in a long life and study process, and is the result of the interaction of various cultural factors. As soon as the world outlook, the outlook on life and the values are formed, it has a definite direction, which has a far-reaching and lasting influence on the comprehensive quality of human beings and the development of life. The influence of a specific culture gene of a country on Chinese people is also subtle. People often consciously accept and strongly agree with the ideas and behaviors they carry and contain, and it is difficult to change. Similarly, the influence of a specific cultural gene of a unit on employees is subtle. People often consciously accept and strongly identify their ideas and behaviors that are contained and implied, and are hard to change. To govern the problem of "lazy government", we must ensure a good cultural environment and form a positive and positive working environment.

Second, the construction of team unity, diligent and eliminate obstacles factors. A unity of a unit has cohesiveness, appeal and combat effectiveness, so that we can bring up the unit construction, and we will produce achievements, cadres and experience. A team must be united and cohesive force to enhance the combat effectiveness of the army so that we can better play the core leadership role, so that we can bring out excellent teams and better accomplish various tasks. The team has been united and has a positive initiative, innovation, responsibility and responsibility for his own work. Between the team members to strengthen cooperation, strengthen cooperation, multi ventilation, multi links, multi coordination, multi support. We regularly inform our members of other teams in a timely manner by taking charge of their main tasks and considering the next work. We should listen to their opinions and suggestions with open heart and ask for their support and cooperation. Team members communicate 
with each other to strengthen, not only make the party's work arrangement, plan, plan more perfect, more targeted, overall, the other party from the lessons learned, increase knowledge, broaden their horizons, inspired by; can also reduce many unnecessary misunderstandings caused by asymmetric information.

Third, remove the vicious competition bad style, follow the capable, concerning the principle of. In the unit, to curry favour chuanxiao xie colleagues complain officials work enthusiasm weakened culture, clear traditional culture officials "complain", "curry favour" dross phenomenon, form a good working atmosphere in the unit within the scope of. He dare not is such a sad affair, formed in the officialdom culture in the bad style of life, making official justice are all gone, if you do not regulate official vicious competition bad style, real general officials did not dare to do, but try to avoid mistakes, "lest I hate eternal".

\subsection{Perfect the System So That the "Lazy Government" Cannot Survive and Develop}

First, to set up an official's disclaimer mechanism and to reduce the excuse of "lazy government". To explore the establishment of tolerance for frustration, failure tolerance, meticulous care system. We should set up a trial and error exemption mechanism to protect the leading cadres who dare to innovate and reform, and give them the opportunity of "trial and error exemption". Let them dare to take risks, dare be a person first, avoid leading cadres for fear of failure and the general practice of some cadres come to a standstill, dispel fear step on the red line, afraid, afraid to touch the vested interest responsibility policy mentality, guide cadres at all levels, as long as the overall reform is beneficial to the development of the party and the state of the system in this field, the favorable formation improve the institutional mechanisms favorable do it boldly [11].

Second, the establishment of effective incentive mechanism and better salary model, in order to reduce the performance of laziness. Motivation has positive and negative incentives, and it also contains many aspects, such as promotion and material incentives for the individual. In the promotion, pay more attention to the application of the results of performance appraisal, reward and application. In response to the social demand is the current government to carry out the work of the foothold, in charge, is a great waste of public resources. Leading officials to dare to do everything and do something should strengthen the positive incentive, in relation to the different positions and career promotion incentive, material incentive is mainly for wages and benefits. In the field of organizational management and behavioral science, there is no lack of proof for the encouragement of organizational members. Barnard regards organizational balance as the problem of contribution (service) and incentive (utility), and the effectiveness that the organization can allocate is no less than its contribution, which is related to the effectiveness of the organization. Guy Peters thought that the stereotyped traditional civil servant reward system that emphasizes unity, 
level and seniority should be gradually replaced by the system of determining the wage level based on the work score, and it should also use the market following mode to give supplementary vocational support [12]. A better salary model should take into account both external fairness and internal differences, and the emphasis on public services should not be deviated. The official salary level should be on the market and the level of labor, to cut off those formed by underpaid and abuse of power and corruption in the chain, the optimization of public service and public officials in the decision-making process of the behavior model, realized by self-interest considerations for the weight of "pure reason" to switch the heavy "public person" for in the public interest, stimulate their initiative to serve the people, as a positive, promote public value regression [13].

Third, in addition, to establish and official authorities, obligations and responsibilities of the corresponding power list. The list of obligations and responsibilities list, clearly defined official obligation and responsibility, so that it cannot be lazy; on the unit leadership officials lazy political behavior for serious rectification, severely punished, with warning function. It cannot be lazy.

\section{Conclusions and Prospect}

The problem of "laziness" has always existed. About five years or so, the Party Central Committee has done its best in the new layout of China. The comprehensive deepening of the reform is a strategy set up in view of the structural transformation requirements of China's reform model. The comprehensive promotion of the rule of law is a path determined by the power defect of the reform and the mechanism of activating the mechanism. However, from the implementation of the situation, the implementation of the two is not as good as people wish. Xi Jinping has made a clear emphasis on the importance and urgency of reforming the issue of landing, that is, from one side. The soft resistance of officials in anti-corruption movement is obvious, and the work motive of officials in the process of anti-corruption remains to be aroused. On the other hand, the status of the ranks of officials, to a certain extent, restricts the effective promotion of the reform. This is not to say that the existing officials are all unwilling to invest in the reform of the decadent cluster, such a judgment may make the ranks of officials feel very grieved. From an objective point of view, it is a serious challenge to promote the way of official team since the reform and opening up, so that, in the face of the new layout of reform, the team of officials is not only difficult to form new consensus, but also difficult to turn to adapt to the new situation.

But this article has some deficiencies: one is lack of empirical examples and the relevant data research; the other one is because my writing level is not good, the writing process is not rigorous enough, the wording may exist some mistakes and not academic. Hope that through more empirical analysis in the days after, to further supplement and improve the content of lazy politics. 


\section{References}

[1] Li, K.Q. The Third Clean Government Conference, the State Council. http://www.gov.cn/xinwen/2014-10/09/content_2761524.htm

[2] http://news.youth.cn/gn/201510/t20151001_7173194.htm

[3] Li, C.C. (2015) The Individual and Organizational Countermeasures of the Official "Lazy Government". The people's forum, 24, 32-43.

[4] Chu, Y.F. (2016) Is Not Official: The Connotation of Logic, Type of Performance and Governance Path. Journal of Henan Normal University (Philosophy and Social Sciences Edition), 6, 59-63.

[5] Meng, Z.B. (2015) Be Vigilant about "Soft Resistance” from "I Am Good”. People's Daily.

[6] Shu, S.F. (2016) From Indiscriminate Politics to Lazy Politics: Internal Mechanism and Policy of Governance. Leadership Science, 3, 8-10.

[7] Xue, H. and Qiu, D. (2016) Mediocre Officers Lazy Politics: A Government Governance Problem of Governance. Yuejiang Academic Journal, 4, 24-26.

[8] Zhang, D. and Liu, W. (2016) The Performance, Causes and Governance of the "Not for the Official" under the New Situation. Management, 10, 277-279.

[9] Xu, Y.T. (2015) Discussion on the Problem of Governance for Officials and Lazy Politics. Journal of Party School of Fujian Provincial Party Committee, 10, 4-8.

[10] China Government Network (2015) Government Work Report. http://www.gov.cn/guowuyuan/2015-03/16/content_2835101.htm

[11] Cao, Q.F. and Zheng, L. (2016) The Long-Term Mechanism of Governing the Phenomenon of "Not Being the Official". Shaanxi Preschool Normal College Journal, 32, $132-135$.

[12] Peters, B. (2001) Government's Future Governance Model. Wu, A.M., et al., Trans. Renmin University of China Press, Beijing, 41-44.

[13] Jin, T.J. and Zhang, J.R. (2016) "Not for the Official" Phenomenon Analysis and Its Regulation. Learning and Exploration, 3, 42-47. 